\title{
Experienced males modify their behaviour during playback: the case of the Chaffinch
}

\author{
Michał Budka $^{1}$ (D) Piotr Matyjasiak ${ }^{2}$ (i) $\cdot$ Jakub Typiak $^{3} \cdot$ Mateusz Okołowski $^{3} \cdot$ Magdalena Zagalska-Neubauer $^{3}(\mathbb{D}$
}

Received: 22 March 2018 / Revised: 1 October 2018 / Accepted: 26 February 2019 / Published online: 19 March 2019

(c) The Author(s) 2019

\begin{abstract}
Animals are able to learn, remember, and make use of previous experiences when making decisions in similar situations, which are some of the most fascinating phenomena in behavioural ecology. However, these cognitive abilities can act as impediments for biologists and ecologists when conducting field studies. Experienced animals may significantly modify their behaviour in subsequent interactions, which could lead to incorrect interpretations of the results of experimental or observational studies of such individuals. In this study we examined whether experienced (lured by playback, caught in a mist net, and handled) Chaffinch males (Fringilla coelebs) modified their behaviour during a subsequent playback experiment in comparison with naive males that had not experienced human contact. We examined 46 individuals, and found that, after experiencing capture and playback, Chaffinch males modified their responses during a playback experiment, at least on a short-term basis. Experienced males modified their vocal behaviour during simulated intrusion within their territory, responding predominantly with calls, while control naive males used mostly territorial songs. We suggest that the higher use of calls by experienced males was a result of their previous negative experience and reflected higher levels of anxiety. The differences in response toward playback between experienced and naive males suggest that special attention must be paid to planning, conducting, and analysing studies when performing multiple experiments on the same group of individuals.
\end{abstract}

Keywords Capture $\cdot$ Bird $\cdot$ Cognition $\cdot$ Pre-exposure effect $\cdot$ Song $\cdot$ Call

\section{Zusammenfassung}

Buchfinken - Erfahrene Männchen modifizieren ihr Verhalten während eines Playback Experiments

Tiere sind in der Lage, zu lernen, sich zu erinnern und für Entscheidungen in ähnlichen zukünftigen Situationen von ihren Vorkenntnissen Gebrauch zu machen. Dies ist eines der faszinierendsten Phänomene in der Verhaltensökologie. Dennoch können diese kognitiven Fähigkeiten als Behinderung für Biologen und Ökologen fungieren, die Freilandstudien durchführen. Erfahrene Tiere können ihr Verhalten für nachfolgende Interaktionen signifikant modifizieren, was zu fehlerhaften Interpretationen der Ergebnisse von experimentellen oder Beobachtungsstudien an solchen Individuen führen könnte. In Rahmen dieser Studie untersuchten wir, inwiefern erfahrene (angelockt mit Klangattrappe, Fang mit Japan-Netz und in die Hand genommen) Buchfinkenmännchen (Fringilla coelebs) ihr Verhalten in einem anschließenden Playback Experiment modifizierten im Vergleich zu naiven Männchen, die zuvor keinen Kontakt mit Menschen hatten. Wir untersuchten 46 Individuen und fanden heraus, dass nach dem Experiment mit Fang und Klangattrappe Buchfinkenmännchen ihre Verhaltensantworten zumindest kurzfristig während des Playbackexperiments änderten. Erfahrene Männchen veränderten ihr Gesangsverhalten während eines simulierten Eindringens in ihr Revier und antworteten vorwiegend mit Rufen, während die naiven Kontrollmännchen in den meisten Fällen ihre Reviergesänge zeigten. Wir vermuten, dass die höhere Rufaktivität der erfahrenen Männchen ein Resultat ihrer vorherigen negativen Erfahrung war und einen höheren Grad von Angst bei

Communicated by S. Kipper.

Electronic supplementary material The online version of this article (https://doi.org/10.1007/s10336-019-01647-w) contains supplementary material, which is available to authorized users.

Extended author information available on the last page of the article 
diesen Männchen widerspiegelt. Die unterschiedlichen Reaktionen von erfahrenen und naiven Männchen gegenüber der Klangattrappe zeigt, dass bei der Planung, Durchführung und Analyse solcher Studien besondere Aufmerksamkeit angeraten ist, wenn mehrfache Experimente an der gleichen Gruppe von Individuen durchgeführt werden.

\section{Introduction}

Animals in the wild experience many different external stimuli from the environment, which can be classified as positive, neutral, or negative. Individuals are able to learn, remember, and make use of previous experiences in assessing risks and making decisions in similar situations (Bradbury and Vehrencamp 2011). For instance, individuals often choose breeding sites that are similar to those in which they were successful in a previous year (Hoover 2003), make repeated visits to well-known, rich feeding sites (Ezaki 1992; Mettke-Hofmann and Gwinner 2003), or use the same safe stopovers during migration (Minias et al. 2010). They may also avoid inedible prey that they tasted in the past (Lynn 2005; Skelhorn et al. 2016), discriminate among different kinds of predators, and employ appropriate strategies to avoid being preyed upon and to increase breeding success (Curio 1975; Kullberg and Lind 2002; Peluc et al. 2008). However, there is justified concern that the ability of animals to acquire experience and to utilise it in future decision-making could bias the results of experimental studies. This is especially true for playback experiments that are used to study acoustic communication. Using this technique, a tested individual is usually exposed many times to various kinds of songs played back from a speaker (e.g. Jabłoński and Matyjasiak 2002; Budka and Osiejuk 2013; Osiejuk 2014). During the experiment, researchers observe and describe in detail the behaviour of the subject (McGregor 2000). It has been shown that birds decrease the intensity of their response during their second exposure to playback, even if the songs in successive treatments are different and played back from different places (Krebs 1976, Rivera-Gutierrez et al. 2017). Reduced aggressiveness after intrusion is usually observed in the short term, such as over a few hours or days (RiveraGutierrez et al. 2017). However, some species are also able to remember the playback experience in the longer term and may reduce the intensity of their response even 1 year after a single playback event (Rivera-Gutierrez et al. 2015). Such plasticity in behaviour is related to a learning and remembering process called "habituation". When individuals experience a potentially threatening event for the first time (e.g. songs played back from a speaker), they respond aggressively. However, when the same threat is repeated many times without consequences for the territory holder, individuals perceive it as non-threatening or irrelevant and respond less intensely in subsequent situations (Dong and Clayton 2009; Harris and Haskell 2013).

Ornithologists often capture birds from the wild during field studies. After capture, birds can be subjected to multiple actions that differ greatly in their invasiveness, such as: taking biometric measurements and weighing; marking with alphanumerical, metal, or colour rings; and blood sampling (e.g. Burton et al. 2006; Ręk et al. 2011; Fourcade et al. 2016). These activities are often necessary to discover and explore the biology and ecology of a species. However, such stressful events related to direct contact with a human could have both short- and long-term effects on individuals, and may alter birds' behaviour after capture (Dubiec 2011; Linhart et al. 2012). Therefore, it is important to know the extent of the influence of capturing and handling on birds' subsequent behaviour. To date, this question has been addressed in only a few studies. For example, Camacho et al. (2017) found that Pied Flycatchers (Ficedula hypoleuca) are more difficult to catch when they have already experienced trapping, which is particularly relevant to the correct interpretation of capture-recapture data. A similar result was reported for the Great Tit (Parus major), in which individuals captured in their nest boxes were more vigilant and hesitated longer before entering nest boxes than individuals that had not been captured (Seress et al. 2017). Linhart et al. (2012) found that capture-experienced males of the Willow Warbler (Phylloscopus trochillus) showed increased response latencies to a playback lure compared to inexperienced birds. Moreover, birds have been shown to distinguish the intentions of a researcher and escape from various distances, depending on whether the researcher approaches them directly or tangentially (Møller and Tryjanowski 2014). Furthermore, Magpies (Pica pica) are even able to distinguish among individual humans and respond more aggressively toward observers who posed a threat to their nests in the past than towards observers who have not previously behaved in a threatening way (Lee et al. 2011). All of the above examples prove that birds learn from negative experiences with humans and that they subsequently increase their vigilance in similar, risky situations. Evolutionarily speaking, these are appropriate behaviours that increase chances of survival. However, this has serious implications for experimental design in biological and ecological studies, as previous experience of humans may strongly affect the response of tested individuals. Usually, experienced birds reduce the intensity of their response and are more cautious than naive ones (Linhart et al. 2012; 
Camacho et al. 2017). The consequence of this behavioural modification is an increase in the probability that any significant effects of the experimental treatment will not be found. Therefore, especially in the case of model species, it is necessary to conduct detailed studies on the consequences of previous experiences on bird behaviour.

In this study we focused on the cumulative effect of a previous playback lure and trapping experience on birds' behaviour during a subsequent playback experiment. Activities such as trapping or luring by playback are commonly undertaken in ornithology, but the consequences of such approaches remain unexplored, and most of the studies using these stimuli have considered the effect of each stimulus separately (e.g. responses to playback in successive playback events or trapping probability in successive trapping approaches). As a focal species we chose the Chaffinch, Fringilla coelebs, a socially monogamous and territorial species, and one of the most common European songbirds. We experimentally examined whether the behaviour of adult (in their second calendar year or older) territorial Chaffinch males during the playback experiment depended on their previous playback and trapping experience. First, we taught individual birds to associate playback with capture by a human, using mist nets to trap birds. Then we performed another playback experiment with a dummy Chaffinch specimen to examine differences in behaviour between the previously captured birds and naive birds with no experience of capture. Thus, in our experiment, birds utilized experiences gained in one context (luring by a playback to the mist net) in another context (simulated intrusion to the territory by a foreign male). We predicted that males that had been previously lured by playback and caught by a mist net (experienced males) would delay their approach and stay further away from the speaker during the subsequent playback experiment compared to males without such experience (naive males). To the best of our knowledge, our study is the second to consider the cumulative effects of a playback lure, capturing and handling on the subsequent behaviour of birds during a playback experiment.

\section{Methods}

\section{Study site}

We conducted our study from 13 April to 15 May 2017. The study site comprised a continuous complex (approximately $3.7 \mathrm{~km}^{2}$ ) of public forests in the suburbs of the city of Warsaw $\left(52^{\circ} 18^{\prime} 58^{\prime \prime} \mathrm{N}, 20^{\circ} 54^{\prime} 50^{\prime \prime} \mathrm{E}\right)$, Poland. From the east, the study area borders the Vistula river, while in the other directions it is surrounded by the city. A two-lane road divides the study area into two parts and generates some traffic noise.
The main forest types were mixed, multi-storey stands and monocultures of Scots pine (Pinus silvestris).

\section{Capture procedure}

We used playback of Chaffinch songs to lure birds, then captured and ringed them. We then performed another playback experiment with both ringed and non-ringed birds to measure their responses to a simulated intruder in their territory. We played back the songs of five different males (25 songs per male), repeated in random order, to catch birds. Birds were captured using ornithological mist nets (Ecotone). A mist net was placed within the territory of a male, the speaker was hung near the net (without a decoy specimen), and a Chaffinch song was played back (we used five different types of songs played randomly; these songs were not used in subsequent playback trials) to attract the male. Capture was not successful in each territory, as we were not able to catch ca. $20-25 \%$ of the males that we approached. Each captured male was measured, weighed with an electronic balance, and marked with a metal alpha-numerical ornithological ring as well as a plastic coloured ring. Samples of blood and feathers were taken, and the male was released in the place of capture. The handling procedure lasted ca. $25 \mathrm{~min}$ and all males were released in good condition.

\section{Playback experiment design}

We tested whether capture-experienced Chaffinch males responded differently than naive males toward intrusion within their territory using playback of a foreign male. Territories of experienced and naive males were visited 1-4 days before the experiment to determine the exact territorial boundaries. For experienced males, the playback experiment was conducted between 2 and 8 days after capture. During the playback experiment, we set a pole $(1.5 \mathrm{~m}$ high $)$ in the middle of the target male's territory with a dummy specimen of a Chaffinch male on top. We used four different dummy males. The speaker (JBL Flip $3 ; 2 \times 8 \mathrm{~W}, 85 \mathrm{~Hz}-20 \mathrm{kHz}$, signal-to-noise ratio $<80 \mathrm{~dB}$, black colour) was placed below the dummy male. We also set eight poles around the speaker (four poles $4 \mathrm{~m}$ from the speaker and four poles $2 \mathrm{~m}$ from the speaker) to better determine the distance between the speaker and the tested male. The playback was turned on (Sony Xperia Z3 connected to the speaker by Bluetooth) only when we were sure that the focal male was present in the territory and located less than $20 \mathrm{~m}$ from the speaker. The amplitude of the playback was set at $81 \pm 3 \mathrm{~dB}$ at $1 \mathrm{~m}$, which corresponds to the average level observed in naturally singing Chaffinch males (Brumm and Ritschard 2011). The experiment comprised three phases ( 3 min each): pre-playback, playback, and post-playback (see Supplementary material S1). During the pre-playback and post-playback phase 
we observed and recorded males' behaviour (for details see below); in the playback phase songs of male Chaffinches were played back with an interval of $7 \mathrm{~s}$ between songs. We used songs of 23 different males (one song per male repeated many times; see Supplementary materials S2) that had been recorded 250-300 km from the study area; we may thus assume that the tested males were not familiar with the experimental songs. Different random combinations of song (one of 23) and dummy Chaffinch male (one of four) were used to test 23 experienced males and 23 naive males. Experienced and naive males were tested in random order; we therefore observed no differences in the stage of the season or the time of day when the experiment was performed for either group of birds. Each experiment was recorded using a Marantz PMD661 digital recorder connected to a Sennheiser ME67 shotgun microphone with a K6 powering module (48 kHz, 16-bit sampling). Two observers (different from those who had captured birds) were located in two different points ca. $15 \mathrm{~m}$ from the speaker during the experiment, to better describe the tested male's behaviour. Playback experiments were conducted from 18 April to 15 May (on average 1 May \pm 7 days), between 0451 and 1023 hours (on average 0711 hours $\pm 85 \mathrm{~min}$; local time).

\section{Measures of males' responses to playback}

The males' behaviour was observed and recorded by a digital recorder during the experiment. Recordings were analysed using Avisoft SasLab Pro software. As measures of the response to playback we used the following vocal characteristics: (1) number of songs, (2) number of "chink" calls (calls uttered during territorial fights or while mobbing ground predators), and (3) number of "hreet" calls (specialised calls uttered mainly in the context of territorial defence or signalling ownership) (Marler 1956) (see Figs. 1; S1). We also recorded characteristics of bird movements during the experiment: (4) number of flights, and (5) minimum distance to the speaker (ordinal variable with three categories: less than $2 \mathrm{~m}, 2-4 \mathrm{~m}$, more than $4 \mathrm{~m}$ ). Additionally, we measured (6) the latency to the first vocal response (song or call), and
(7) latency to the first flight. Latency-related responses were defined as the time (in seconds) from the beginning of the first song of playback to the first vocalisation or first flight; thus a lower value indicated a faster approach. Finally, during each experiment, observers assessed whether a female was in sight. Since both males and females produce chink calls, the microphone was always directed at the focal male. If a female started calling, the observer recorded which calls belonged to the male and which to the female. In this way we minimised the probability that a female's calls would be classified as a male's.

\section{Statistical analyses}

We analysed each measure of male behaviour separately to examine in detail which behavioural variables of the tested males were modified by their previous experience of a playback lure and human capture. First, we examined whether experienced and naive males differed in behaviour during the pre-playback phase, when only observers were present within a territory (Mann-Whitney test). Next, we investigated how intrusion by a foreign male (simulated by playback) modified the behaviour of the territory holder independently of their experience of capture by humans. We compared changes in a given male's behaviour during the three phases of the experiment-pre-playback, playback, and post-playback - using generalised estimating equations (GEE). We constructed a separate GEE model for each of the measures of males' behaviour that could be observed in each phase of the experiment: (1) the number of songs, (2) the number of chink calls, (3) the number of hreet calls, and (4) the number of flights. Dependent variables were fitted using a negative binomial distribution and log link function. The predictor variables were: (1) phase of the experiment (categorical predictor), (2) date when the experiment was conducted (continuous predictor), (3) hour when the experiment started (continuous predictor), and (4) the presence of a female during the experiment (categorical predictor). We used main effect models with intercepts included in the models. We based the covariance matrix on a robust estimator

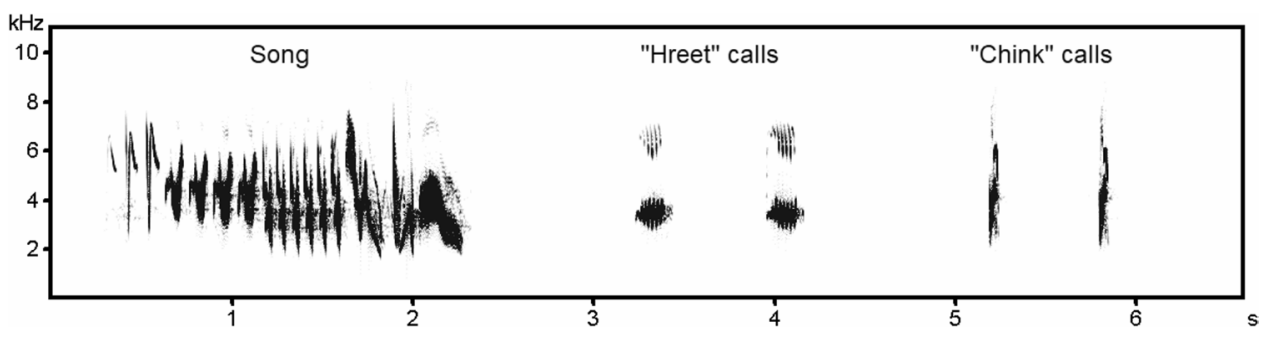

Fig. 1 Three measures of the acoustic response of Chaffinch males: song, "hreet" calls, and "chink" calls. Spectrogram were generated in Avisoft Sas Lab Pro software with the following settings: fast Fou- rier transform $=512$, frame size $=75 \%$, windows $=$ hamming, overlap $=75 \%$. For the original recording, see Supplementary material (S1) 
and we specified the working correlation matrix (i.e. withinsubject dependencies) as independent (i.e. repeated measurements are uncorrelated).

Differences in behaviour between capture-experienced and naive males during the playback phase were analysed using generalised linear models. We constructed separate models for each of the measures of male behaviour: (1) the number of songs, (2) the number of chink calls, (3) the number of hreet calls, (4) the number of flights, (5) latency to the first vocal response, (6) latency to the first flight, and (7) and minimum distance to the speaker. As predictors we used: (1) treatment (categorical predictor), (2) presence of a female during the experiment (categorical predictor), (3) date when the experiment was conducted (continuous predictor), and (4) hour when the experiment started (continuous predictor). We fitted data using a negative binomial distribution and $\log$ link function (predictors 1-4), a gamma distribution and $\log$ link function (predictors 5-6), and a multinomial distribution with cumulative probit link function (predictor 7). Analogous models were run for the post-playback phase. However, for these we considered only the first four measures of male behaviour, since only those measures could be observed at this stage of the experiment.

All statistical analyses were performed using IBM SPSS software version 24 . When necessary, the normality of variables was examined using the Kolmogorov-Smirnov test. All $p$-values are two-tailed. We applied a Holm-Bonferroni correction to counteract the problem of multiple comparisons (Holm 1979).

\section{Results}

\section{Male behaviour during pre-playback phase}

We tested 46 Chaffinch males-23 experienced and 23 naive individuals - to examine whether previous playback and capture experiences affected birds' behaviour during a subsequent playback experiment. We did not find significant differences in behaviour between experienced and naive males during the 3-min pre-playback phase (Table 1). During this phase males usually spent time in one place (performed from zero to three flights), sung on average eight songs (range
0-25), uttered a few hreet calls (on average 5.5, range 0-122) and even fewer chink calls (on average 1.5, range 0-36).

\section{The effect of playback on male behaviour}

The tested males significantly modified their behaviour in response to playback. During the playback phase, males significantly increased the number of flights and the number of chink calls, while simultaneously decreasing the number of songs sung with respect to both the pre-playback and post-playback phase (Table 2). Hreet calls were significantly more frequent during the post-playback phase than during the playback phase. All analysed measures of male response correlated weakly with each other (Pearson correlation;

Table 2 Results of four generalised estimating equations comparing the behaviour of Chaffinch males during the three phases of the experiment

\begin{tabular}{llrrc}
\hline Model & Predictors & Wald $\chi^{2}$ & $d f$ & \multicolumn{1}{l}{$p$} \\
\hline No. of flights & Intercept & 1.08 & 1 & 0.292 \\
& Phase & 147.440 & 2 & $<0.001^{* * *}$ \\
& Female & 3.280 & 1 & 0.070 \\
& Date & 0.115 & 1 & 0.734 \\
No. of songs & Hour & 0.056 & 1 & 0.813 \\
& Intercept & 3.907 & 1 & 0.048 \\
& Phase & 8.060 & 2 & $0.018^{*}$ \\
& Female & 2.815 & 1 & 0.093 \\
No. of hreet calls & Date & 0.022 & 1 & 0.882 \\
& Hour & 0.012 & 1 & 0.911 \\
& Intercept & 0.530 & 1 & 0.466 \\
& Phase & 13.034 & 2 & $0.001^{* * *}$ \\
& Female & 0.001 & 1 & 0.988 \\
& Date & 0.454 & 1 & 0.500 \\
& Hour & 0.001 & 1 & 0.996 \\
No. of chink calls & Intercept & 0.819 & 1 & 0.366 \\
& Phase & 32.595 & 2 & $<0.001^{* * *}$ \\
& Female & 0.713 & 1 & 0.399 \\
& Date & 0.883 & 1 & 0.347 \\
& Hour & 1.944 & 1 & 0.163 \\
\hline
\end{tabular}

Dependent variables were fitted with a negative binomial distribution and log link function; intercept included in all models

$* p \leq 0.05, * * * p \leq 0.001$ (significant predictors after Holm-Bonferroni correction)
Table 1 Comparison of behaviour of experienced and naive male Chaffinches during the 3-min pre-playback phase

\begin{tabular}{lllll}
\hline Measure of behaviour & Experienced males & Naive males & $Z$ & $p$ \\
\hline Number of flights & $0.5(0.85)$ & $0.7(0.82)$ & -1.248 & 0.212 \\
Number of songs & $7.6(7.50)$ & $8.6(7.67)$ & -0.365 & 0.715 \\
Number of "hreet" calls & $4.7(17.03)$ & $6.3(25.56)$ & -0.427 & 0.669 \\
Number of "chink" calls & $0.6(1.90)$ & $2.3(7.71)$ & -0.732 & 0.464 \\
\hline
\end{tabular}

Mean values $( \pm \mathrm{SD}), Z$-statistics (Mann-Whitney test) and $p$-values are given 
songs and hreet calls, $r=-0.238, p=0.005$; songs and chink calls, $r=-0.284, p=0.001$; songs and flights, $r=-0.268$, $p=0.001$; hreet calls and chink calls, $r=0.136, r=0.111$; hreet calls and flights, $r=-0.006, p=0.944$; chink calls and flights, $r=0.285, p=0.001$ ). The effects of the presence of a female during the experiment, or the date and hour when the experiment was conducted, were not significant in any model (Table 2; Fig. 2).

\section{The effect of experience on male behaviour during the playback phase}

Experienced males differed in behaviour compared to naive males during the 3-min playback phase. Experienced males sang less often and were less likely to approach closely to the speaker $(<2 \mathrm{~m}$; result not significant after Holm-Bonferroni correction) compared to naive males (Table 3; Figs. 3, 4). Instead, experienced males produced significantly more calls (hreet and chink) than naive males (Table 3; Fig. 3). We did not find any significant differences in the number of flights or the latency to vocal and flight responses between experienced and naive males (Table 3; Fig. 3). The number of hreet calls significantly decreased over the course of the day, while the number of chink calls increased. The number of songs in this phase of the experiment decreased with the progression of both the season and the day; however, the effects of hour and stage of season were very small compared to the capture-experience effect and not significant after applying Holm-Bonferroni correction (Table 3). We found only three significant correlations between analysed measures of males' responses (Pearson correlation; number of songs and number of chink calls, $r=-0.293, p<0.05$; number of flights and latency of flight, $r=-0.470, p<0.001$; latency of flight and latency of vocal response, $r=0.389, p<0.05$ ).

\section{The effect of experience on male behaviour during the post-playback phase}

Analyses of males' behaviour during the post-playback phase showed that experienced males produced significantly more chink calls than naive males. There were no significant differences for the other three measures of birds' responses (numbers of flights, songs, and hreet calls) between naive and experienced males (Table 4; Fig. 5). However, our models showed that males modified their behaviour depending on the presence of a female during the experiment: males
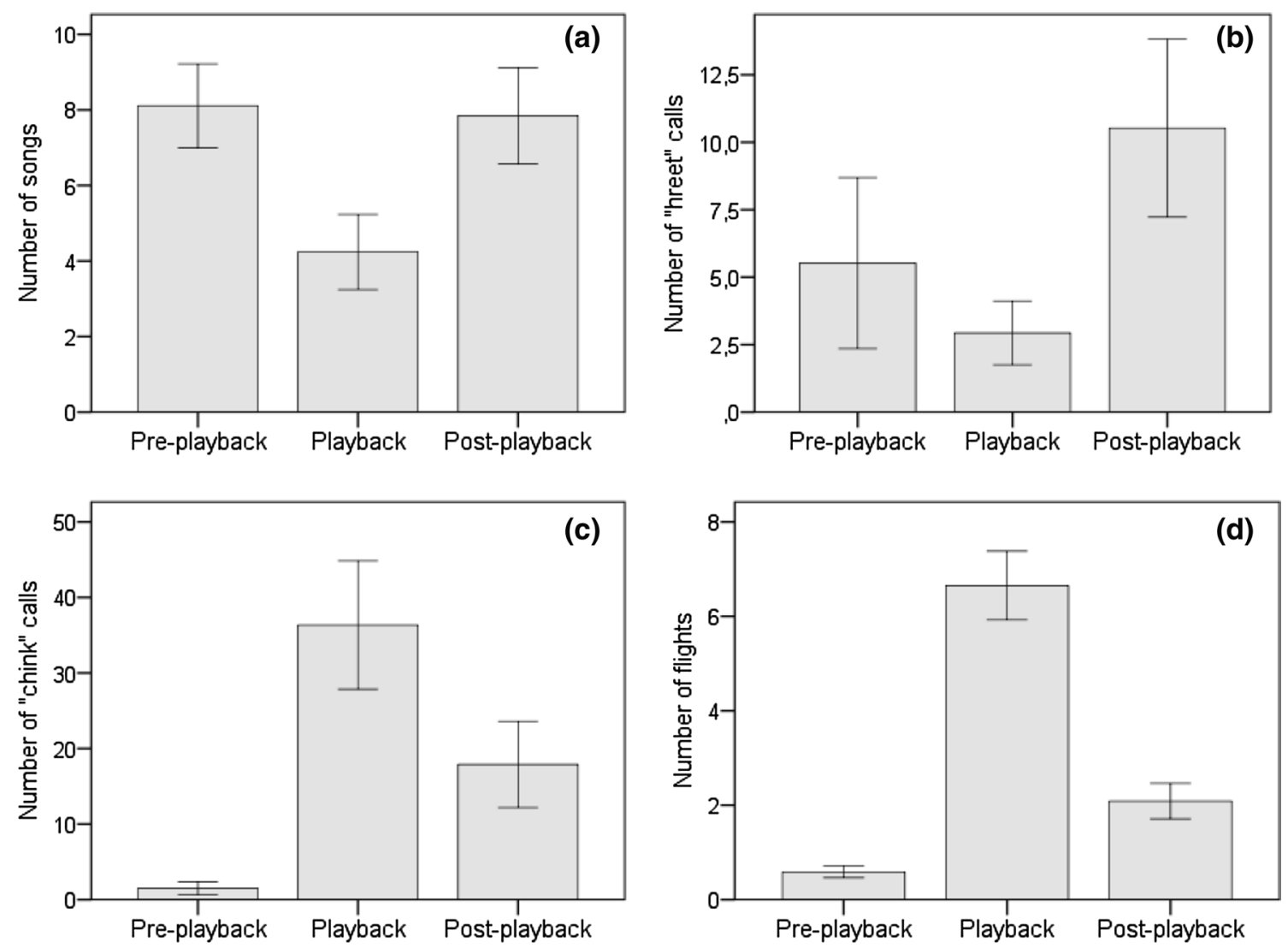

Fig. 2 Chaffinch males' behaviour during the three phases of the experiment: pre-playback, playback, and post-playback. Mean values and SEM are given. Experienced and naive males are considered together 
Table 3 Results of seven generalised linear models investigating the behaviour of male Chaffinches as a function of experience (experienced vs. naive males), the presence of a female during the test (present-absent), and the date and time (h) of the test

\begin{tabular}{|c|c|c|c|c|c|c|}
\hline \multirow[t]{2}{*}{ Model } & $B$ & Wald $\chi^{2}$ & $p$ & $B$ & Wald $\chi^{2}$ & $p$ \\
\hline & \multicolumn{3}{|c|}{ Number of flights (1) } & \multicolumn{3}{|c|}{ Number of songs (2) } \\
\hline Intercept & 1.989 & 4.638 & 0.031 & 3.893 & 14.154 & $<0.001 * * *$ \\
\hline Experience & 0.290 & 0.720 & 0.396 & 1.250 & 8.368 & $0.004 * *$ \\
\hline Female & 0.380 & 0.879 & 0.349 & -0.437 & 1.182 & 0.277 \\
\hline Date & -0.100 & 0.169 & 0.681 & -0.069 & 5.979 & 0.014 \\
\hline Hour & 0.001 & 0.020 & 0.886 & -0.005 & 4.076 & 0.044 \\
\hline \multirow[t]{2}{*}{ Model } & $B$ & Wald $\chi^{2}$ & $p$ & $B$ & Wald $\chi^{2}$ & $p$ \\
\hline & \multicolumn{3}{|c|}{ Number of hreet calls (3) } & \multicolumn{3}{|c|}{ Number of chink calls (4) } \\
\hline Intercept & 1.471 & 1.703 & 0.192 & 2.587 & 7.045 & $0.008 * *$ \\
\hline Experience & -1.419 & 13.353 & $<0.001 * * *$ & -1.068 & 11.506 & $0.001 * * *$ \\
\hline Female & 0.490 & 1.052 & 0.305 & 0.250 & 0.412 & 0.521 \\
\hline Date & 0.048 & 2.081 & 0.149 & -0.006 & 0.056 & 0.813 \\
\hline Hour & -0.009 & 7.457 & $0.006^{* *}$ & 0.008 & 12.489 & $<0.001 * * *$ \\
\hline \multirow[t]{2}{*}{ Model } & $B$ & Wald $\chi^{2}$ & $p$ & $B$ & Wald $\chi^{2}$ & $p$ \\
\hline & \multicolumn{3}{|c|}{ Latency to vocal response (5) } & \multicolumn{3}{|c|}{ Latency to flight response (6) } \\
\hline Intercept & 3.538 & 14.080 & $<0.001 * * *$ & 4.017 & 17.059 & $<0.001$ \\
\hline Experience & 0.115 & 0.154 & 0.695 & -0.252 & 0.709 & 0.400 \\
\hline Female & -0.378 & 1.015 & 0.314 & -0.031 & 0.008 & 0.930 \\
\hline Date & 0.022 & 0.827 & 0.363 & 0.019 & 0.631 & 0.427 \\
\hline Hour & -0.003 & 1.825 & 0.174 & -0.004 & 2.275 & 0.131 \\
\hline \multirow[t]{2}{*}{ Model } & & $B$ & & Wald $\chi^{2}$ & & $p$ \\
\hline & \multicolumn{5}{|c|}{ Minimal distance to the speaker (7) } & \\
\hline Distance $=3$ & & 0.660 & & 0.365 & & 0.546 \\
\hline Distance $=2$ & & 1.314 & & 1.430 & & 0.232 \\
\hline Experience & & 0.788 & & 4.443 & & 0.035 \\
\hline Female & & 0.241 & & 0.303 & & 0.582 \\
\hline Date & & -0.001 & & 0.001 & & 0.970 \\
\hline Hour & & 0.001 & & 0.175 & & 0.675 \\
\hline
\end{tabular}

Data were fitted using a negative binomial distribution and log link function (models 1-4), a gamma distribution and log link function (models 5-6), and a multinomial distribution with cumulative probit link function (model 7). Reference categories for categorical predictors: experience-experienced male, female—absent

$* * p \leq 0.01, * * * p \leq 0.001$ (significant predictors after Holm-Bonferroni correction)

accompanied by a female flew more often and produced fewer hreet calls than males around which a female was not observed during this phase of the experiment (effects not significant after Holm-Bonferroni correction). Also, the hour of the experiment had a significant but very weak effect on the number of hreet calls produced in the post-playback phase (Table 4; Fig. 5).

\section{Discussion}

We applied a typical approach that is used in many biological and ecological studies of birds: we caught individuals, and a few days after this negative experience for the birds, we performed a playback experiment. As a control group, we used males that did not have this type of experience of humans. There were no significant differences in behaviour during the pre-playback phase between these two groups of males when the speaker, dummy male, and observers were within the territory of a target individual but the song playback had not yet begun. This suggests that both naive and experienced birds do not treat a human presence in their territory as a threat in itself, at least during the pre-playback phase. We also observed no significant differences in the number of flights and latency to the first flight or vocal response during the playback phase ( 3 min, during which a song of a foreign male was played back from the speaker). These two measures of a bird's response-number of flights 

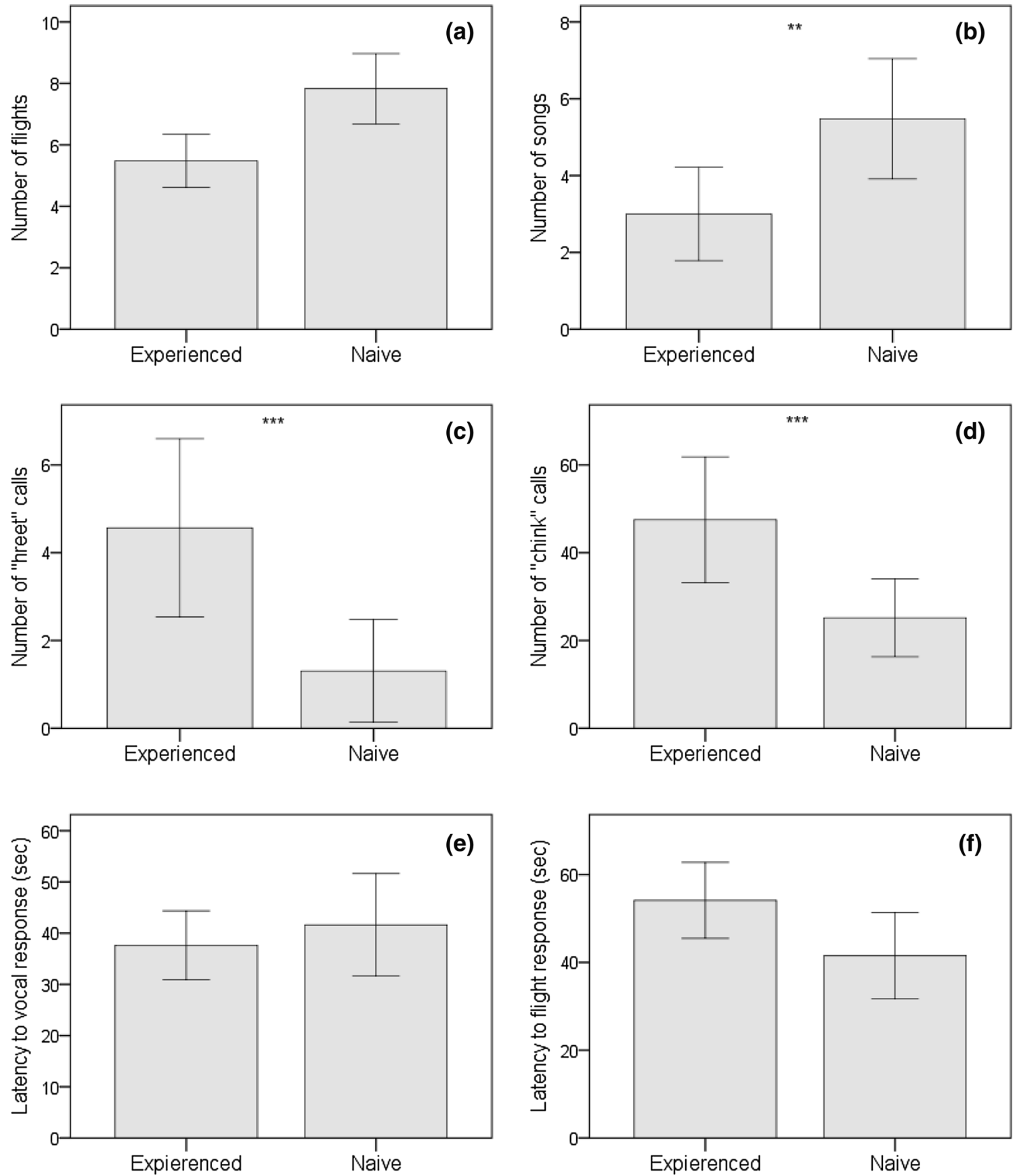

Fig. 3 Differences in response during the playback phase between experienced and naive Chaffinch males. Bars denote means, whiskers denote SEs. $* * p<0.01, * * * p<0.001$; for more details, see Table 3

and latency to response- are often used to describe birds' behaviour during playback experiments (e.g. Skierczyński et al. 2007; Brumm and Ritschard 2011), and here, these measures were independent of the previous experience of tested males. It seems that, after an acoustic intrusion, the territory holders tried to locate the intruder as fast as possible, regardless of any previous experience of lure by playback and capture by humans. However, this pattern seems to be species specific, since in the Willow Warbler, captureexperienced males increased latency to response to playback compared to naive males (Linhart et al. 2012). This difference may result from different strategies of territorial defence among species. For example, Brumm and Ritschard (2011) found that Chaffinch males spent more time within $5 \mathrm{~m}$ of the speaker and approached closer to the speaker when songs of lower amplitude were played back. In the 


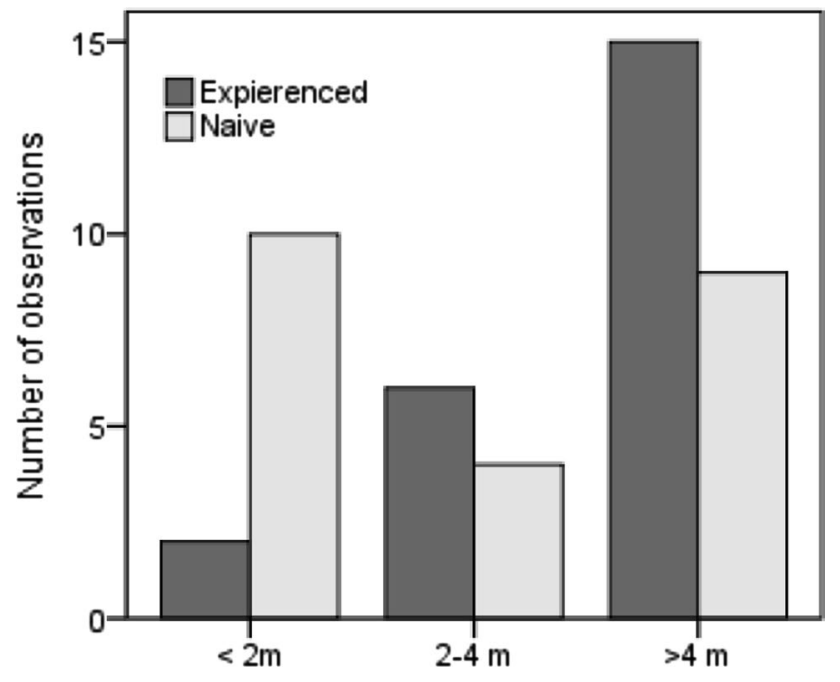

Fig. 4 Differences in the approach to the speaker between experienced and naive males during the playback phase. Number of males observed within each distance category (minimal distance) to the speaker are given

same experiment they found no significant differences in the number of flights and latency of response during the playback. That indicates that Chaffinch males respond just as quickly and fly with the same intensity in response to all intruders but change their distance to the perceived threat depending on the type of intruder. The opposite pattern was observed in the Willow Warbler. In this species, males flew less and were slower to approach the speaker in response to playback of a neighbour with which they shared the border of their territory than in response to playback of a more distant male, but there was no significant difference with respect to the number of songs and latency to sing (Jaška et al. 2015).

In contrast to latency and the number of flights, other measures of Chaffinch males' responses depended on differences in the previous experiences of tested birds. During the playback phase, experienced males did not approach as closely to the speaker as naive birds; however, this measure of response was not significant when we applied Holm-Bonferroni correction for multiple testing. Similar results have been reported in other studies that examined the influence of human-induced disturbances on birds' later behaviour (Camacho et al. 2017; Harris and Haskell 2013; Lima and Roper 2009; Rivera-Gutierrez et al. 2015). Thus, a commonly used measure of birds' response to playback-the time spent within a certain distance of the speaker (e.g. $5 \mathrm{~m}$ in Budka and Osiejuk 2013; Wei et al. 2011)—can strongly depend on a tested individual's previous experience of capture by humans. Therefore, it is possible that the same experiment performed on experienced or naive males may result in completely different results (i.e. significant or not) when the response variable examined is, for example, a minimumapproach distance or time spent within $5 \mathrm{~m}$ of the speaker (Brumm and Ritschard 2011). Another problem is that the results of studies based on naive and experienced males cannot be directly compared. These are serious challenges for the planning, execution, and analysis of research based on individuals that have been captured by a researcher. The simplest way to overcome this problem is to use study sites or populations that have not been disturbed by capture or luring by playback (Rivera-Gutierrez et al. 2015). Alternatively, when playback experiments are carried out on experienced males,

Table 4 Results of four generalised linear models comparing the behaviour of tested Chaffinch males during the post-playback phase

\begin{tabular}{|c|c|c|c|c|c|c|}
\hline \multirow[t]{2}{*}{ Model } & $B$ & Wald $\chi^{2}$ & $p$ & $B$ & Wald $\chi^{2}$ & $p$ \\
\hline & \multicolumn{3}{|c|}{ Number of flights (1) } & \multicolumn{3}{|c|}{ Number of songs (2) } \\
\hline Intercept & 0.566 & 0.284 & 0.594 & 2.725 & 7.370 & 0.007 \\
\hline Capture experience & -0.028 & 0.005 & 0.942 & 0.618 & 2.297 & 0.130 \\
\hline Female & 0.851 & 3.858 & 0.050 & -0.307 & 0.423 & 0.515 \\
\hline Date & 0.011 & 0.182 & 0.670 & -0.023 & 0.794 & 0.373 \\
\hline Hour & -0.002 & 1.047 & 0.306 & -0.001 & 0.169 & 0.681 \\
\hline \multirow[t]{2}{*}{ Model } & $B$ & Wald $\chi^{2}$ & $p$ & $B$ & Wald $\chi^{2}$ & $p$ \\
\hline & \multicolumn{3}{|c|}{ Number of hreet calls (3) } & \multicolumn{3}{|c|}{ Number of chink calls (4) } \\
\hline Intercept & 1.007 & 0.739 & 0.390 & 1.678 & 3.009 & 0.083 \\
\hline Capture experience & 0.115 & 0.115 & 0.734 & -1.481 & 14.097 & $<0.001 * * *$ \\
\hline Female & -1.127 & 5.547 & 0.019 & 0.056 & 0.018 & 0.894 \\
\hline Date & 0.006 & 0.037 & 0.847 & 0.029 & 1.252 & 0.263 \\
\hline Hour & 0.007 & 7.725 & $0.005 * *$ & 0.004 & 3.040 & 0.081 \\
\hline
\end{tabular}

Reference categories for categorical predictors: experience-experienced male, female—absent

$* * p \leq 0.01, * * * p \leq 0.001$ (significant predictors after Holm-Bonferroni correction) 

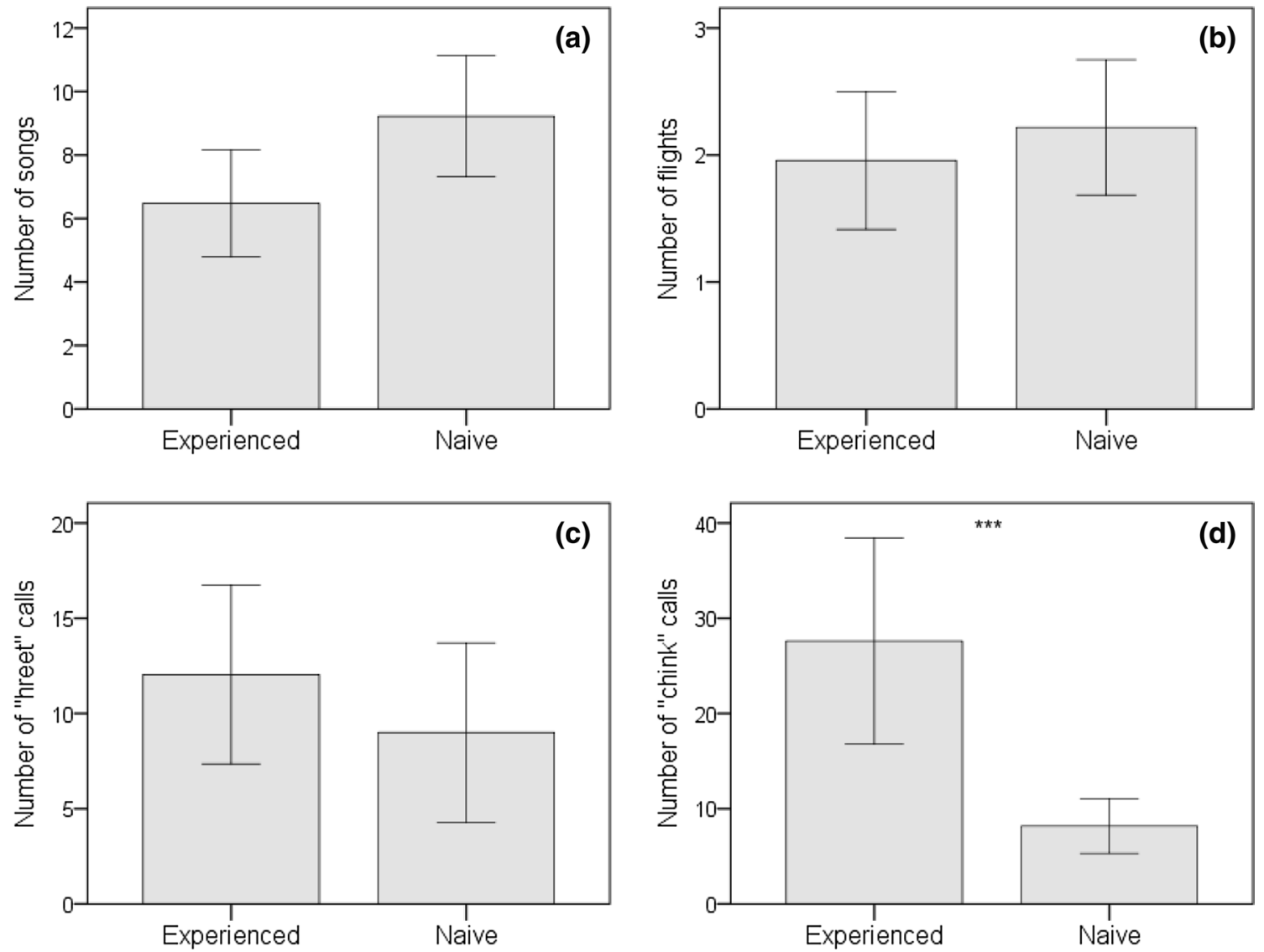

Fig. 5 Chaffinch males' behaviour during the post-playback phase. Only significant effects are shown (see Table 4). Differences in the number of songs (a), number of flights (b), number of "hreet" calls

it may be helpful to increase the area (distance from the lure) within which the individual is recorded (e.g. time spent 5, 10 , or $15 \mathrm{~m}$ from the speaker). Other options for experiments that include both naive and experienced individuals could be to account for species-specific responses in the design and planning of behavioural experiments, and to add human disturbance in the data analysis as an ordered factor.

In most other studies, the response most often associated with successive approaches to the same individual was a decreasing intensity of vocal response, related to habituation-a learning process in which individuals decrease or cease their responses to a stimulus after its repeated or prolonged presentations (Dong and Clayton 2009). Instead, we found that naive and experienced males demonstrated contrasting vocal behaviour during the playback phase of the experiment, i.e. naive males sung significantly more often while experienced males produced more chink and hreet calls. One of the most important functions of bird song is rival deterrence, while calls are produced in particular contexts, related to specific functions such as signalling a threat or alarm, mobbing, or expressing emotions (Catchpole and Slater 2008). Therefore, naive males, which are not familiar

and number of "chink" calls between experienced and naive males are given. Mean values and SE are shown. $* * * p<0.001$. For more details see Table 4

with playback and humans, respond to playback by singing. Such behaviour could be considered a typical reaction to playback, which has been observed in many bird species in the context of territorial defence (Bradley and Mennill 2009; Osiejuk 2014). However, the experienced individuals might recall the negative experience of capture (associated with luring by playback, capturing, and handling) and be more vigilant in a similar risky situation (Linhart et al. 2012; Harris and Haskell 2013). Additionally, playback has been reported to change daily individual activity (Mennill et al. 2002; Langham et al. 2006) and influence hormone secretion, particularly by elevating corticosterone and testosterone levels (Wingfield 1985; Wingfield et al. 2001). Furthermore, birds exposed to playback alter their vocal activity, but not always in the same way [i.e. some increase their vocal activity while others decrease it (Harris and Haskell 2013)]. Increased vocalisation requires higher energy expenditure, which could be regarded as an increase in physiological costs. In contrast, decreases in vocalisation over time could be explained by a process of habituation to playback. This type of result was previously noted during playback experiments on the Plain-tailed Wren (Pheugopedius euophrys) 
(Harris and Haskell 2013), and we observed a similar reaction here in the Chaffinch.

Experienced males used alarm calls instead of territorial song. Interestingly, the hreet and chink calls seem to have different functions (Marler 1956, 2004). Chink calls were observed extremely rarely during the pre-playback phase; males produced them mostly during the playback phase and less often during the post-playback phase. This suggests that chink calls could be an alarm signal related to high levels of stress, and may be produced by both males and females in various risky situations (Marler 1956, 2004). The opposite pattern was observed for the hreet calls, which were the most numerous during the post-playback phase and less frequent during the playback phase. Moreover, Chaffinch males are able to change the amplitude of hreet calls (personal observations) in a way that is similar to their manipulation of song amplitude (Brumm and Ritschard 2011). Song amplitude in Chaffinch is an aggressive signal, and playback of loud songs from a speaker elicits a stronger response from males (Brumm and Ritschard 2011). Therefore, we hypothesise that hreet calls may serve a similar function to songs, and may be used in aggressive interactions between males in order to evaluate the quality of an intruder.

Our study showed that experienced and naive males responded differently to the same playback treatment. Although the experienced birds were familiar with playback and certain humans, the main playback experiment used a different type of songs than those used to lure birds for initial capture, and the observers during the main experiment were not the same humans who had captured birds initially. It seems possible, then, that experienced birds may modify their behaviour and respond differently than naive males not only to playback but also in interactions with other males. Alternatively, experienced males may be able to distinguish between recorded songs and a natural male's song, or they may recognise and associate the two types of threat-human presence and playback of song - and modify their behaviour only when both threats are present. The question of which mechanism is at work in Chaffinches is still open, as it is for many other bird species. In any event, future studies should include preliminary tests of the effect of birds' previous experience of capture by humans on their subsequent responses to playback. If these tests reveal strong biases in the response of experienced birds to playback, alternative capture methods should be considered (such as capture at the nest), or subsequent playback experiments should target only inexperienced birds.

In conclusion, our study showed that Chaffinch males' previous experiences of humans and song playback modify their behaviour during a subsequent playback experiment, at least in the short term. Experienced males modified their vocal behaviour by responding predominantly with alarm calls, while naive males tended to use song in response to a simulated intrusion within a territory. We hypothesise that experienced males' memory of capture and their awareness of the circumstances surrounding that negative experience cause a high level of stress and anxiety, which the males may express using calls instead of songs. This change of playback-induced expression of behaviour needs more examination in a physiological context, especially regarding hormone-behaviour interrelationships. The differences shown here between naive and experienced males in response to playback are strong evidence that great care must be taken in planning, conducting, and analysing experiments that involve the repeated use of the same subjects.

Acknowledgements We would like to thank Aleksandra Kaźmierska and Maciej Fuszara for their help with the fieldwork, Tomasz Osiejuk and Pavel Linhart for helpful comments on the manuscript, Lindsay Higgins for language correction, Krzysztof Deoniziak for the recordings used to prepare playback, and two anonymous reviewers for helpful comments on the manuscript. The study was financially supported by the Polish National Science Centre (grant no. 2014/15/B/NZ8/00272 awarded to Magdalena Zagalska-Neubauer).

\section{Compliance with ethical standards}

Ethics This study was conducted according to Polish law. We obtained all required permissions to conduct the study: permission of the Ethics Committee on Animal Experiments (no. 021/2016) and permission of the Regional Directorate of Environment Protection (no. WPN.I.6401.73.2016.EB.2). The birds were caught under licenses issued by the Polish Bird Ringing Centre.

Sound archive The sound recordings are available at https://doi. org/10.7479/dk01-d7yf.

Open Access This article is distributed under the terms of the Creative Commons Attribution 4.0 International License (http://creativeco mmons.org/licenses/by/4.0/), which permits unrestricted use, distribution, and reproduction in any medium, provided you give appropriate credit to the original author(s) and the source, provide a link to the Creative Commons license, and indicate if changes were made.

\section{References}

Bradbury JW, Vehrencamp SL (2011) Principles of animal communication. Sinauer, Sunderland

Bradley DW, Mennill DJ (2009) Song ungraded response to playback of solo, duets and choruses in a cooperatively breeding neotropical songbird. Anim Behav 77:1321-1327

Brumm H, Ritschard M (2011) Song amplitude affects territorial aggression of male receivers in Chaffinches. Behav Ecol 22:310-316

Budka M, Osiejuk TS (2013) Neighbour-stranger call discrimination in a nocturnal rail species, the Corncrake Crex crex. J Ornithol 154:685-694

Burton NHK, Rehfisch MM, Clark NA, Dodd SG (2006) Impacts of sudden winter habitat loss on the body condition and survival of Redshank Tringa totanus. J Appl Ecol 43:464-473

Camacho C, Canal D, Potti J (2017) Lifelong effects of trapping experience lead to age-biased sampling: lessons from a wild bird population. Anim Behav 130:133-139 
Catchpole CK, Slater PJB (2008) Bird song. Biological themes and variation, 2nd edn. Cambridge University Press, Cambridge

Curio E (1975) The functional organization of anti-predator behaviour in the Pied Flycatcher: a study of avian visual perception. Anim Behav 23:1-115

Dong S, Clayton DF (2009) Habituation in songbirds. Neurobiol Learn Mem 92:183-188

Dubiec A (2011) Condition-dependent clutch desertion in Great tit (Parus major) females subjected to human disturbance. J Ornithol 152:743-749

Ezaki Y (1992) Importance of communal foraging grounds outside the reed marsh for breeding Great Reed Warblers. Ecol Res 7:63-70

Fourcade Y, Richardson DS, Keišs O, Budka M, Green RE, Fokin S, Secondi J (2016) Corncrake conservation genetics at a European scale: the impact of biogeographical and anthropological processes. Biol Conserv 198:210-219

Harris JBC, Haskell DG (2013) Simulated birdwatchers' playback affects the behavior of two tropical birds. PLoS One 8:e77902

Holm S (1979) A simple sequentially rejective multiple test procedure. Scan J Stat 6:65-70

Hoover JP (2003) Decision rules for site fidelity in a migratory bird, the Prothonotary Warbler. Ecology 84:416-430

Jabłoński P, Matyjasiak P (2002) Male wing-patch asymmetry and aggressive response to intruders in the Common Chaffinch (Fringilla coelebs). Auk 119:566-572

Jaška P, Linhart P, Fuchs R (2015) Neighbour recognition in two sister songbird species with a simple and complex repertoire-a playback study. J Avian Biol 45:151-158

Krebs JR (1976) Habituation and song repertoires in Great Tit. Behav Ecol Sociobiol 1:215-227

Kullberg C, Lind J (2002) An experimental study of predator recognition in Great Tit fledgings. Ethology 108:429-441

Langham GM, Contreras TA, Sieving KE (2006) Why pishing works: Titmouse (Paridae) scolds elicit a generalized response in bird communities. EcoScience 13:485-496

Lee WY, Lee S, Choe JC, Jablonski PG (2011) Wild birds recognize individual humans: experiments on Magpies, Pica pica. Anim Cogn 14:817-825

Lima AMX, Roper JJ (2009) The use of playbacks can influence encounters with birds: an experiment. Rev Bras Ornitol 17:37-40

Linhart P, Fuchs R, Poláková S, Slabbekoorn H (2012) Once bitten twice shy: long-term behavioural changes caused by trapping experience in Willow Warblers Phylloscopus trochilus. J Avian Biol 43:186-192

Lynn SK (2005) Learning to avoid aposematic prey. Anim Behav 70:1121-1226

Marler P (1956) Behaviour of the Chaffinch Fringilla coelebs. Behaviour Suppl.:III-184

Marler P (2004) Bird calls: a cornucopia for communication. In: Marler $\mathrm{P}$, Slabbekoorn H (eds) Nature's music. The science of birdsong. Elsevier, Amsterdam, pp 132-177

McGregor PKM (2000) Playback experiments: design and analysis. Acta Ethol 3:3-8
Mennill DJ, Ratcliffe LM, Boag PT (2002) Female eavesdropping on male son contests in songbirds. Science 296:873

Mettke-Hofmann C, Gwinner E (2003) Long-term memory for a life on the move. PNAS 100:5863-5866

Minias P, Kaczmarek K, Wlodarczyk R, Janiszewski T, Bargiel R (2010) Feeding conditions determine return rates to stopover sites of inland waders on autumn migration. Ibis 152:840-844

Møller AP, Tryjanowski P (2014) Direction of approach by predators and flight initiation distance of urban and rural populations of birds. Behav Ecol 25:960-966

Osiejuk TS (2014) Differences in frequency of shared song types enables neighbour-stranger discrimination in a songbird species with small song repertoire. Ethology 120:893-903

Peluc SI, Sillett TS, Rotenberry JT, Ghalambor CK (2008) Adaptive phenotypic plasticity in an island songbird exposed to a novel predation risk. Behav Ecol 19:830-835

Ręk P, Osiejuk TS, Budka M (2011) Functionally similar acoustic signals in the Corncrake (Crex crex) transmit information about different states of the sender during aggressive interactions. Horm Behav 60:706-712

Rivera-Gutierrez H, Pinxten R, Eens M (2015) Songbirds never forget: long-lasting behavioural change triggered by a single playback event. Behaviour 152:1277-1290

Rivera-Gutierrez HF, Martens T, Pinxten R, Eens M (2017) Learning speed is affected by personality and reproductive investment in a songbird. PLoS One 12(10):e0185410

Seress G, Vincze E, Pipoly I, Hammer T, Papp S, Preiszner B, Bokony V, Liker A (2017) Effects of capture and video-recording on the behavior and breeding success of Great Tit in urban and forest habitats. J Field Ornithol 88:299-312

Skelhorn J, Halpin CG, Rowe C (2016) Learning about aposematic prey. Behav Ecol 27:955-964

Skierczyński M, Czarnecka KM, Osiejuk TS (2007) Neighbour-stranger song discrimination in territorial Ortolan Bunting Emberiza hortulana males. J Avian Biol 38:415-420

Wei M, Lloyd H, Zhang Y (2011) Neighbour-stranger discrimination by Yellow-bellied Tit Parus venustulus: evidence for the "dearenemy" effect. J Ornithol 152:431-438

Wingfield JC (1985) Short-term changes in plasma levels of hormones during establishment and defense of a breeding territory in male Song Sparrows, Melospiza melodia. Horm Behav 19:174-187

Wingfield JC, Lynn SE, Soma KK (2001) Avoiding the 'costs' of testosterone: ecological bases of hormone-behavior interactions. Brian Behav Evol 57:239-251

Publisher's Note Springer Nature remains neutral with regard to jurisdictional claims in published maps and institutional affiliations.

\section{Affiliations}

\section{Michał Budka ${ }^{1}$ (D) Piotr Matyjasiak ${ }^{2}$ (D) Jakub Typiak ${ }^{3} \cdot$ Mateusz Okołowski $^{3} \cdot$ Magdalena Zagalska-Neubauer $^{3}$ (D)}

Michał Budka m.budka@amu.edu.pl

1 Department of Behavioural Ecology, Faculty of Biology, Adam Mickiewicz University in Poznan, Umultowska 89, 61-614 Poznan, Poland
2 Faculty of Biology and Environmental Sciences, Cardinal Stefan Wyszyński University in Warsaw, Wóycickiego 1/3, PL-01-938 Warsaw, Poland

3 Ornithological Station, Museum and Institute of Zoology Polish Academy of Sciences, Wilcza 64, 00-679 Warsaw, Poland 